\section{Enzymatic quantification and length determination of polyphosphate down to a chain length of two ${ }^{1}$}

Jonas J Christ, Lars M Blank

Institute of Applied Microbiology, RWTH Aachen University, Worringer Weg 1, 52074 Aachen

jonas.christ@rwth-aachen.de

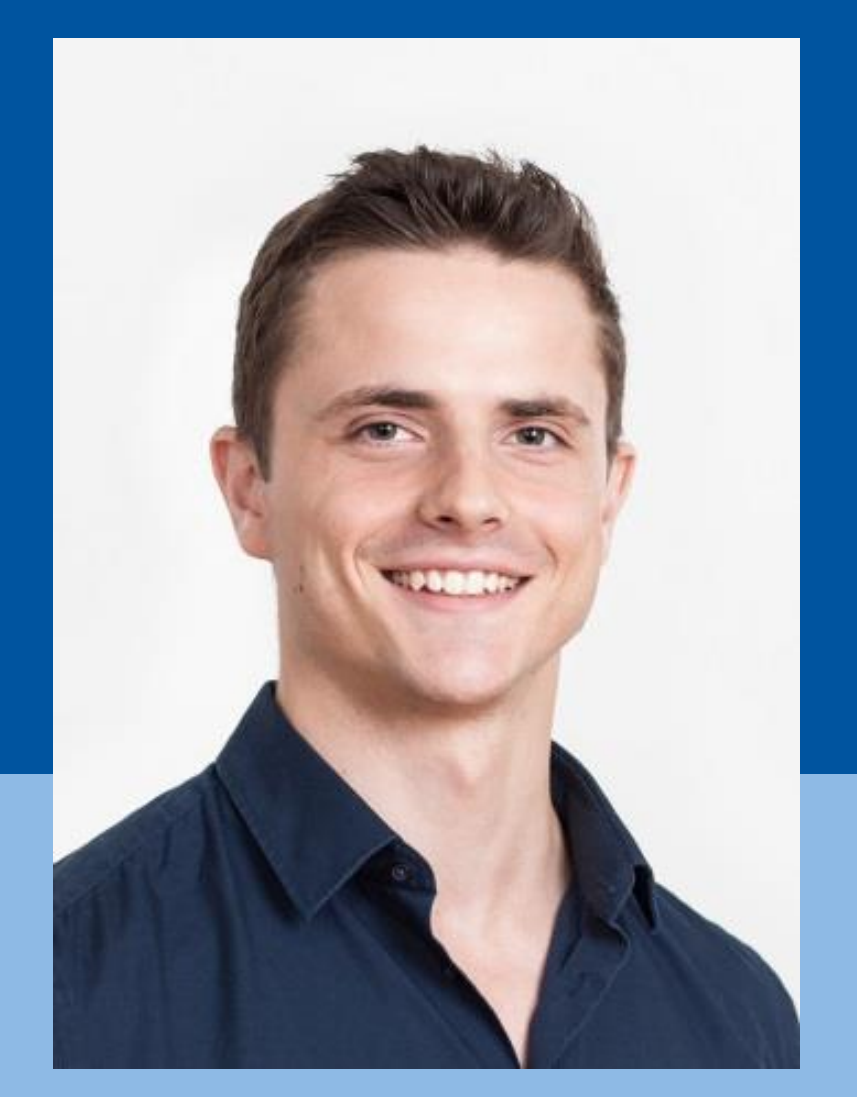

\section{Introduction and goal}

Inorganic polyphosphate can be found as a linear polymer of orthophosphate (polyP) in all living organisms. To study polyP in organisms, analytical methods for both polyP quantification and length determination are required, which are insensitive to common biological impurities and allow higher throughput.

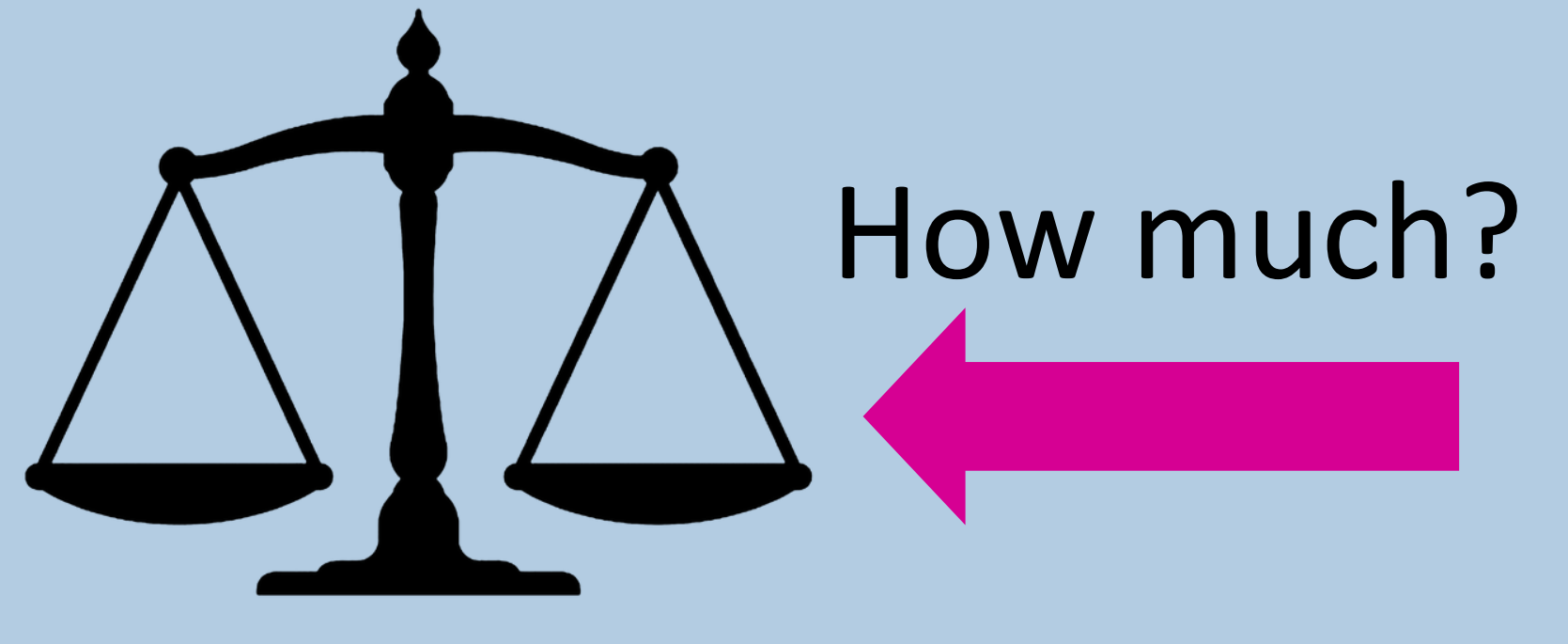
polyphosphate
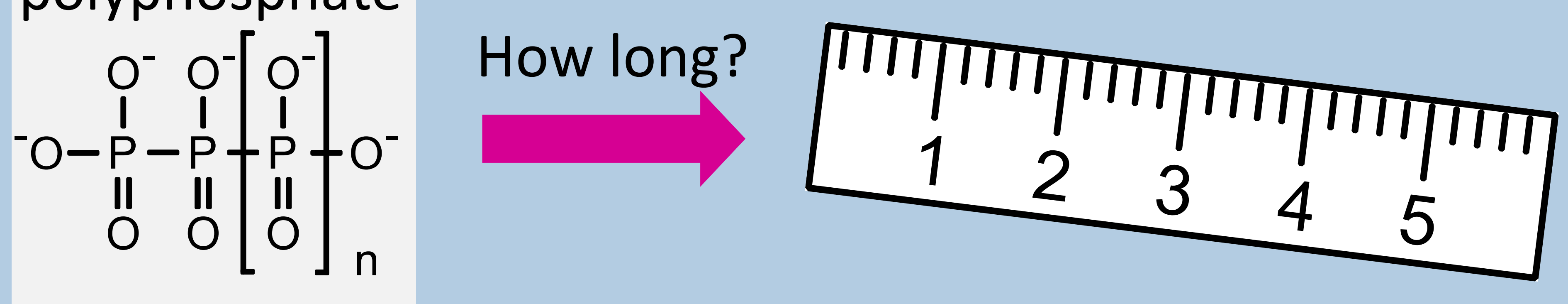

The aim of this study was to develop an enzymatic method for both comprehensive quantification of polyP and determination of the average polyP chain length from biological samples.

\section{II}

\section{Results}

First, a colorimetric assay for orthophosphate detection was developed. Features of the assay:

- Addition of only one reagent to the sample

- Full color development in < 2 min

- Linear range: 5 to $200 \mu \mathrm{M}$ orthophosphate

- Negligible hydrolysis of polyP during orthophosphate determination

\section{III}

\section{Results 2}

Based on the colorimetric assay, a new assay for polyP quantification and chain length determination was developed. See Fig. 1 for the work flow and equation 1 for calculation of the average chain length.

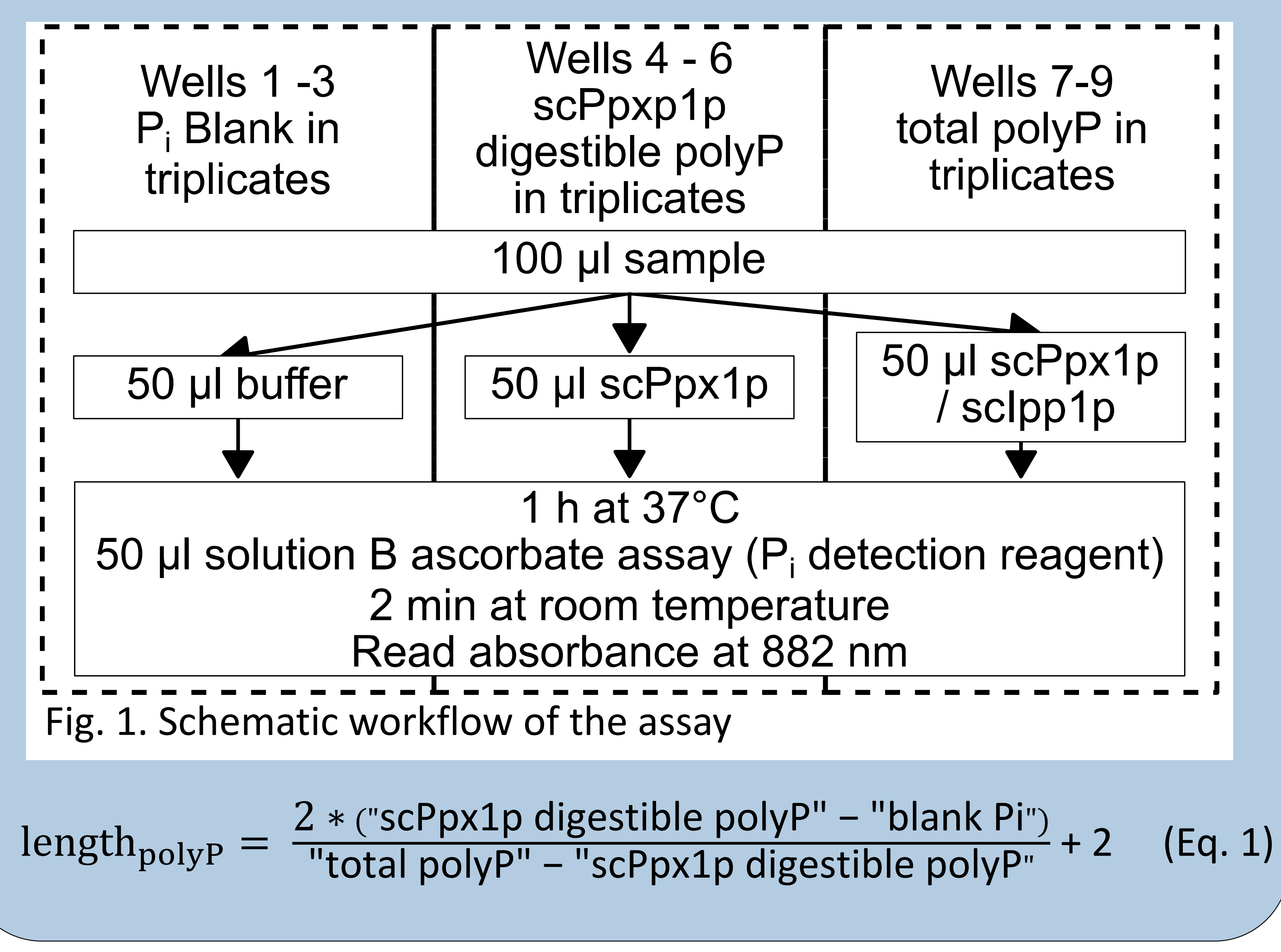

\section{IV}

\section{Results 3}

Characteristics of the new assay for polyP quantification and length determination:

- Use of Saccharomyces cerevisiae exopolyphosphatase 1 and S. cerevisiae inorganic pyrophosphatase 1

- Comprehensive quantification of polyP of all chain lengths

- Average polyP chain length of short chain polyP can be quantitatively determined (Table 1 )

- Common biological impurities (DNA, RNA, ATP etc.) do not interfere with the assay

- $2 \mathrm{~h}, 1.5 \mu \mathrm{g}$ polyP and a plate reader required

Table 1. Comparision enzyme assay vs. gold standard (titration)

\begin{tabular}{ccc}
\hline \multirow{2}{*}{ PolyP } & \multicolumn{2}{c}{ Mean chain length \pm SEM } \\
\cline { 2 - 3 } & Enzyme assay & Titration \\
\hline Triphosphate & $3.1 \pm 0.0$ & n. d. \\
Budit 9 & $3.8 \pm 0.0$ & $4.1 \pm 0.0$ \\
PolyP from & $11.8 \pm 0.1$ & $10.8 \pm 0.0$ \\
Sigma & $12.6 \pm 0.3$ & $11.9 \pm 0.0$ \\
Budit 7 & $25.7 \pm 2.3$ & $21.2 \pm 0.1$ \\
Budit 4 & $27.9 \pm 2.7$ & $24.6 \pm 0.1$ \\
\hline
\end{tabular}

\section{Conclusion}

We present an enzymatic assay that allows for the first time both comprehensive polyP quantification, and length determination of short chain polyP. 